\title{
Design and Analysis of the Effect of Zeonex Based Octagonal Photonic Crystal Fiber for Different Types of Communication Applications
}

Selim Hossain ( $\nabla$ selimtee@gmail.com )

KYAU https://orcid.org/0000-0003-0715-4873

M. M. Kamruzzaman

Jouf University

Shuvo Sen

Mawlana Bhashani Science and Technology University

Mir Mohammad Azad

Khwaja Yunus Ali University

\section{Research Article}

Keywords: Zeonex Based O-PCF, EML loss, Larger Effective Area, High Core Power Fraction, SM-OPCF, Scattering Loss

Posted Date: May 10th, 2021

DOl: https://doi.org/10.21203/rs.3.rs-462789/v1

License: (9) This work is licensed under a Creative Commons Attribution 4.0 International License. Read Full License

Version of Record: A version of this preprint was published at Optical and Quantum Electronics on July 9th, 2021. See the published version at https://doi.org/10.1007/s11082-021-03084-7. 


\title{
Design and Analysis of the Effect of Zeonex Based Octagonal Photonic Crystal Fiber for Different Types of Communication Applications
}

\author{
Md. Selim Hossain', M. M. Kamruzzaman², Shuvo Sen ${ }^{3 *}$, Mir Mohammad Azad ${ }^{4}$ \\ ${ }^{1}$ Department of Computing and Information System (CIS), Daffodil International University, \\ Dhaka, Bangladesh. \\ ${ }^{2}$ Department of Computer Science, College of Computer and Information Sciences, Jouf \\ University, Sakakah, KSA \\ ${ }^{3}$ Department of Information and Communication Technology (ICT), Mawlana Bhashani Science \\ and Technology University (MBSTU), Santosh, Tangail-1902, Bangladesh \\ ${ }^{4}$ Department of Computer Science and Engineering, Khwaja Yunus Ali University, Enayetpur, \\ Sirajganj-6751, Bangladesh \\ *Corresponding Author: Mawlana Bhashani Science and Technology University, Santosh, \\ Tangail-1902, Bangladesh \\ Email: $\underline{\text { shuvombstu.it12009@gmail.com }}$
}

\begin{abstract}
In this present work, a novel structure of octagonal cladding with two elliptical air holes based on photonic crystal fiber (O-PCF) has been presented for the application of different types of communication areas within the terahertz $(\mathrm{THz})$ wave propagation. There are five layers of octagonal design shape of circular air holes $(\mathrm{CAH})$ in cladding region with elliptical design shape of two air holes in core area has been reported in this research work. This O-PCF fiber has been investigated by the perfectly matched layers (PML) with the finite element method (FEM). After the simulation process, our proposed O-PCF fiber shows a low effective material loss (EML) of $0.0162 \mathrm{~cm}^{-1}$, the larger effective area of $5.88 \times 10-8 \mathrm{~m} 2$, the core power fraction (PF) of $80 \%$, the scattering loss of $1.22 \times 10^{-10} \mathrm{~dB} / \mathrm{km}$, and the confinement loss of $3.33 \times 10^{-14} \mathrm{~dB} / \mathrm{m}$ at the controlling region of 1 terahertz $(\mathrm{THz})$. Due to its excellent characteristics, this proposed O-PCF fiber gives proficient transmission of broadband terahertz waves of signals. Moreover, for different kinds of optical communication applications and biomedical signals, our suggested OPCF fiber will be highly perfect in the terahertz (THz) regions.
\end{abstract}

Keywords: Zeonex Based O-PCF, EML loss, Larger Effective Area, High Core Power Fraction, SM-OPCF, Scattering Loss. 


\section{Introduction}

In present times, Terahertz (THz) radiation which varying from 0.1 to $10 \mathrm{THz}$ has gained considerable interest due to its numerous functional uses related to electromagnetic radiation. The range of $\mathrm{THz}$ frequency deceits the region between the microwave and infrared radiation (IR) in the electromagnetic spectrum (ES). In wavelength, this range corresponds to $0.1 \mathrm{~mm}$ to infrared to $1 \mathrm{~mm}$ microwave. The $\mathrm{THz}$ frequency spectrum shows interesting development in the field of sensors [1-3], pharmaceutical medical testing [4], restorative spectrometry [5], biomedical imaging [6], therapeutic diagnostics [7-8], DNA hybridization [6], communications [9], etc. The radiation of terahertz $(\mathrm{THz})$ ranges has been also utilized within the areas of diagnostics such as skin cancer, basal cell carcinoma, and dysplastic skin nevi, etc. [10]. On the other hand, colon cancer and breast cancer can be carried out to prevent these diseases by utilizing high-frequency $\mathrm{THz}$ radiation.

Besides, hollow-core photonic crystal fiber and polymer fibers can be connected for $\mathrm{THz}$ communication since of their outstanding waveguide perspectives [9-10]. Recently, porous core PCFs have gained considerable interest because of their adaptability in structural nature and required optical controlling possessions such as high core power fraction, lower effective material loss, lower dispersion, lower bending loss, high nonlinearity [18-23]. Modified Total internal refection (MTIR) and photonic band gap (PGB) are two basic optical guiding properties are found in PCF. Total internal reflection (TIR) and photonic bandgap (PGB) are two basic optical guiding properties are found in PCF. If the light is confined in a higher region of the refractive index in solid-core PCF then the total internal reflection can be optimized. Various polymer is used as background materials in microstructure core PCF to control the optical guiding properties such as TOPAS, Tellurite, Zeonex, Graphene, Teflon, etc. [24-26].

Many researchers have been examined the performance of PCF structures previously using the terahertz $(\mathrm{THz})$ waveguides [26-30]. Islam et al. [31] proposed a porous-core spiral shape photonic crystal fiber (PCF). Their proposed model obtained the EML and effective area of 0.1 $\mathrm{cm}^{-1}$ and $1.82 \times 10^{-7} \mathrm{~m}^{2}$ accordingly at $1 \mathrm{THz}$ frequency. Nonetheless, their proposed model showed higher EML. Hasan et al. [32] explored hexagonal PCFs which gained EML of 0.089 $\mathrm{cm}^{-1}$ at $1 \mathrm{THz}$ frequency. But some of the essential parameters were not listed in his article. At the same time, Saiful et al. [33] suggested a rotated hexagonal porous core with circular shape cladding and found the EML of $0.053 \mathrm{~cm}^{-1}$ with a dispersion of $0.25 \mathrm{ps} / \mathrm{THz} / \mathrm{cm}$. Rana et al. [34] proposed a hexagonal-shaped hole incorporated within the core of a Kagome lattice PCF. Their proposed model shows an EML of $0.029 \mathrm{~cm}^{-1}$ and a core power fraction of $33 \%$ at $1.3 \mathrm{THz}$ frequency. In the same year, Sultana et al. [35] designed a hexagonal shape cladding with elliptical core PCF to obtain an EML of $0.05 \mathrm{~cm}^{-1}$ and a very high birefringence of 0.086 . 
Besides their suggested model obtained comparably higher EML and some important elements like power fraction and bending loss stayed unexplored.

In this article, the newly designed Zeonex based octagonal shape of the cladding region with two elliptical shapes in the core area has been introduced in the $\mathrm{THz}$ regime. The proposed model shows an extremely low effective material loss (EML) of $0.0162 \mathrm{~cm}^{-1}$ with $80 \%$ core power fraction and larger effective area (EA) of $5.88 \times 10^{-8} \mathrm{~m}^{2}$ at $1 \mathrm{THz}$ optical frequency than the previously published articles [35-42].

\section{Design Methodology of the Single Mode PCF}

The geometry view of O-PCF has been provided in Fig.1 that has two elliptical shape air holes in the core region with five layers octagonal shape circular air holes of cladding region along with the mode field distribution. The number of $1 \mathrm{st}, 2 \mathrm{nd}, 3 \mathrm{rd}, 4 \mathrm{th}$, and 5 th layer of air holes are 8,16 , 32,64 , and 128 within the cladding region correspondingly. Here, the pitch and diameter of the air holes are marked by parameters of $\mathrm{P}_{1}$ and $\mathrm{m}_{1}$ respectively at the cladding region. The parameters ratio of $m_{1} / P_{1}$ is called the air filling ratio and these $m_{1} / P_{1}$ ratio try to reduce the fabrication complexity between the two air holes at the cladding region. On the other hand, the parameters of $\mathrm{p}_{\mathrm{c}}, \mathrm{m}_{\mathrm{a}}$, and $\mathrm{m}_{\mathrm{b}}$ are denoted with the pitch and diameters of the two elliptical air holes at the core area. Here, Zeonex is used as background material to reduce the effective material loss, confinement loss and the scattering loss for various communication application areas. Besides, the optimum parameters are diameter of cladding $\mathrm{m}_{1}=244 \mu \mathrm{m}, \mathrm{m}_{2}=\mathrm{m}_{3}=\mathrm{m}_{4}=$ $\mathrm{m}_{5}=272 \mu \mathrm{m}$, pitch of cladding $\mathrm{P}_{1}=325 \mu \mathrm{m}, \mathrm{P}_{2}=\mathrm{P}_{3}=\mathrm{P}_{4}=\mathrm{P}_{5}=365 \mu \mathrm{m}$, diameter of core $\mathrm{m}_{\mathrm{a}}=$ $74 \mu \mathrm{m}, \mathrm{m}_{\mathrm{b}}=195 \mu \mathrm{m}$ and core pitch $\mathrm{P}_{\mathrm{c}}=90 \mu \mathrm{m}$ and the thickness of PML (boundary condition) is calculated by the $8 \%$ of the maximum fiber diameter. Consequently, this O-PCF structure is designed by the FEM method with the PML layers based COMSOL Multiphysics software tool and helps to achieve the better optical features such as scattering loss, effective area, power fraction, the ultra-low effective material loss (U-EML), V-parameter, confinement loss from 0.80 to $3 \mathrm{THz}$ with the terahertz frequency wave pulse ranges. 

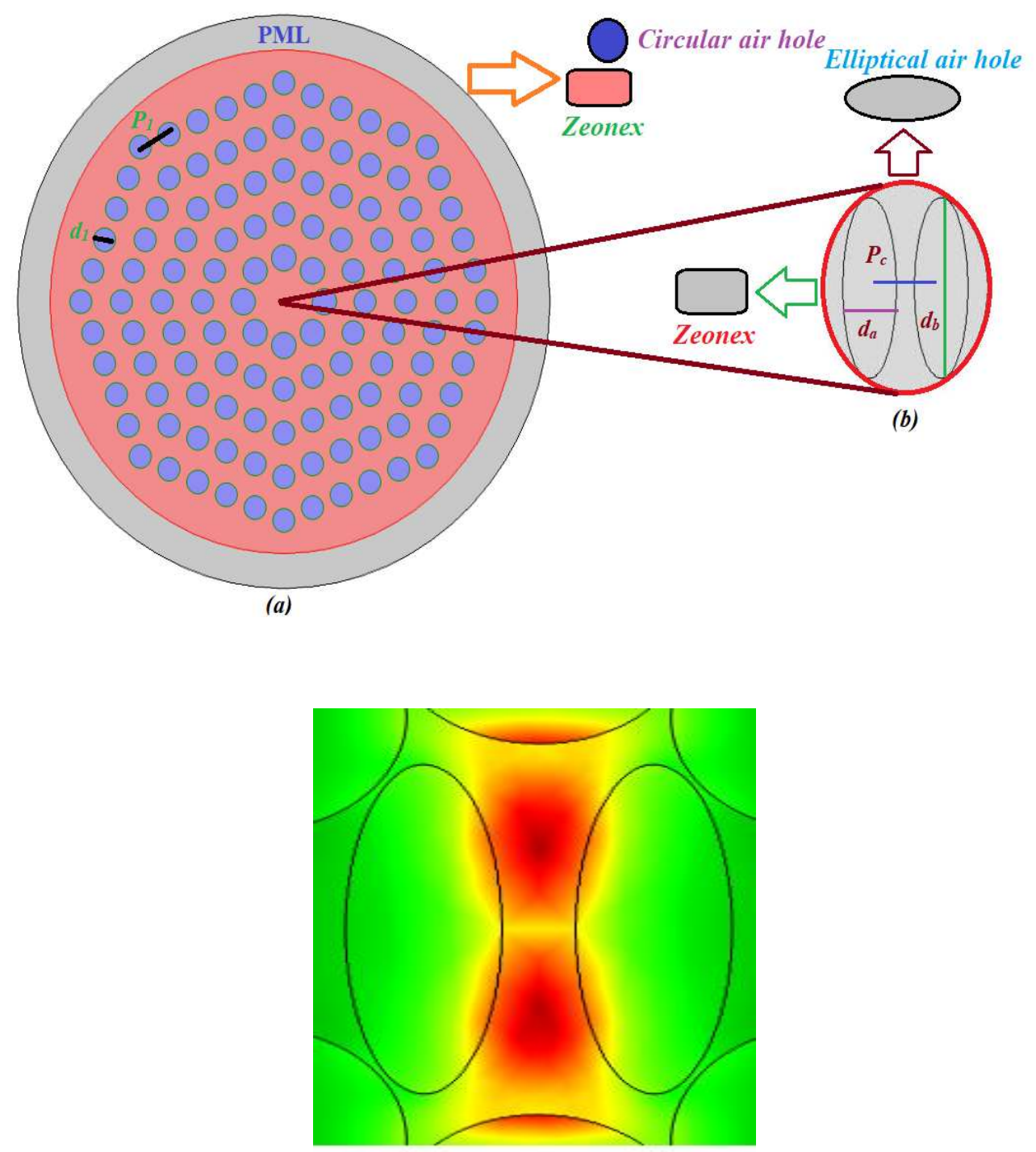

(c) Mode field distribution

Figure 1: Designing views of O-PCF fiber, (a) Octagonal cladding area (b) Elliptical core area (c) Mode field distribution.

\section{Analysis of Optical Properties:}

To plan and reconstruct the highlights of the current O-PCF, the finite element method (FEM) is available in COMSOL Multiphysics $4.2 \mathrm{~b}$ software. Between the final ring of the cladding region and the core region, the boundary condition perfectly matched layers (PML) are used. The FEM with PML technique, which uses the COMSOL Multiphysics software tool, includes all optical 
angles and parameters. We know that a larger effective area-based PCF fiber shows better communication in many sectors. Here, the effective area is expressed by [27-28]:

$$
\mathrm{A}_{\mathrm{ea}}=\frac{\left[\int I(e) e d e\right]^{2}}{\left[\int I^{2}(e) d e\right]^{2}}
$$

Where, $\mathrm{I}(\mathrm{e})=\left|\mathrm{E}_{\mathrm{e}}\right|^{2}$ is the intensity electric field and effective area $=\mathrm{A}_{\mathrm{ea}}$.

One more important property of optical fiber is the power fraction that is determined with the total amount of power through the PCF fiber. Here, the power fraction is calculated by the following equations [29-30]:

$$
\eta=\frac{\int_{\mathrm{i}} S_{z t} d A t}{\int_{\text {all }} S_{z t} d A t}
$$

Where, the integration of nominator is defined by the region of interest such as the cladding, core or air hole and the whole cross-section area is indicated by the integration of denominator.

Mode propagation of O-PCF is mentioned by $\mathrm{V}$-parameter. Here, V-parameter is analyzed by [31]:

$$
\mathrm{V}=\frac{2 \pi e f}{c} \sqrt{\mathrm{ne}^{2}{ }_{\text {coe }}-\mathrm{ne}^{2} \text { cle }} \leq 2.045
$$

Where, $\mathrm{n}_{\text {coe }}$ and $\mathrm{n}_{\text {cle }}$ is determined by the core and cladding area based on effective refractive index and the radius of the core is e.

Low confinement loss based O-PCF structure shows better performance in the communication areas. Here, confinement loss $\mathrm{L}_{\mathrm{C}}$ is calaulted by [32]:

$$
\mathrm{L}_{\mathrm{c}}=8.686 \times \mathrm{K}_{0} \operatorname{Im}\left[\mathrm{n}_{\mathrm{ea}}\right](\mathrm{dB} / \mathrm{m})
$$

Where, $K_{0}=\left(\frac{f}{c}\right)$ is the free wave number with the speed of photon $\mathrm{c}$ and $\mathrm{f}$ is frequency, $\operatorname{Im}\left[\mathrm{n}_{\mathrm{ea}}\right]$ is well-defined by the imaginary part of effective refractive index (ERI).

The total amount of loss can be calculated by the scattering of the O-PCF fiber. Here, the scattering loss is totaled by [33]:

$$
\alpha_{S}=C_{S} \times\left(\frac{f}{c}\right)^{4}(d B / k m)
$$


Where, $C_{S}$ is denoted by the scattering coefficient with $f$ is frequency and $c$ is the speed of photon.

TOPAS is the background material of O-PCF fiber and supports to reduce the effective material loss (EML) with the wide band frequency range. So, effective material loss (EML) is determined by [36-38]:

$$
\alpha_{\mathrm{ea}}=\sqrt{\frac{\varepsilon_{0}}{\mu_{0}}}\left(\frac{\int_{\mathrm{mat}} n_{\text {mat }|E|^{2} \alpha_{\mathrm{mat}} d A t}}{\left|\int_{\text {all }} S_{z t} d A t\right|}\right)\left(\mathrm{cm}^{-1}\right)
$$

Where, $\varepsilon_{0}=$ relative permittivity and $\mu_{0}=$ the permeability of free space, $\mathrm{n}_{\text {mat }}=$ Refractive index of the material and $\alpha_{\text {mat }}=$ bulk material absorption loss, Pointing vector $S_{\mathrm{zt}}=\frac{1}{2}\left(\mathrm{E} \times \mathrm{H}^{*}\right)$. The component of electric field (E) and magnetic field $\left(\mathrm{H}^{*}\right)$ which are the complex parameters.

\section{Simulated Results Analysis and Discussions:}

We have found the complete graphical results from the PML layers and the FEM method based COMSOL Multiphysics software tool of this single mode photonic crystal fiber. From Figure 2 to 9, it is clearly seen that the total amount of lights transmits within the core area. As a result, this O-PCF fiber shows better graphical results about of optical properties like as low effective material loss (EML), scattering loss, larger effective area, high core power fraction (CPF), Vparameter, confinement loss with the frequency ranges from 0.08 to 3 terahertz $(\mathrm{THz})$.

The effective area along with different frequency as well as functional porosity for instance $63 \%$, $73 \%$, and $83 \%$ have been given by the Figure 2 . The effective area is decreased with the increasing frequency ranges that has been shown in Figure 2. Here, the effective area is calculated as $5.88 \times 10^{-8} \mathrm{~m}^{2}, 6.20 \times 10^{-8} \mathrm{~m}^{2}$, and $6.05 \times 10^{-8} \mathrm{~m}^{2}$ for $83 \%, 73 \%$, and $63 \%$ porosities respectively at 1 terahertz $(\mathrm{THz})$ frequency. 


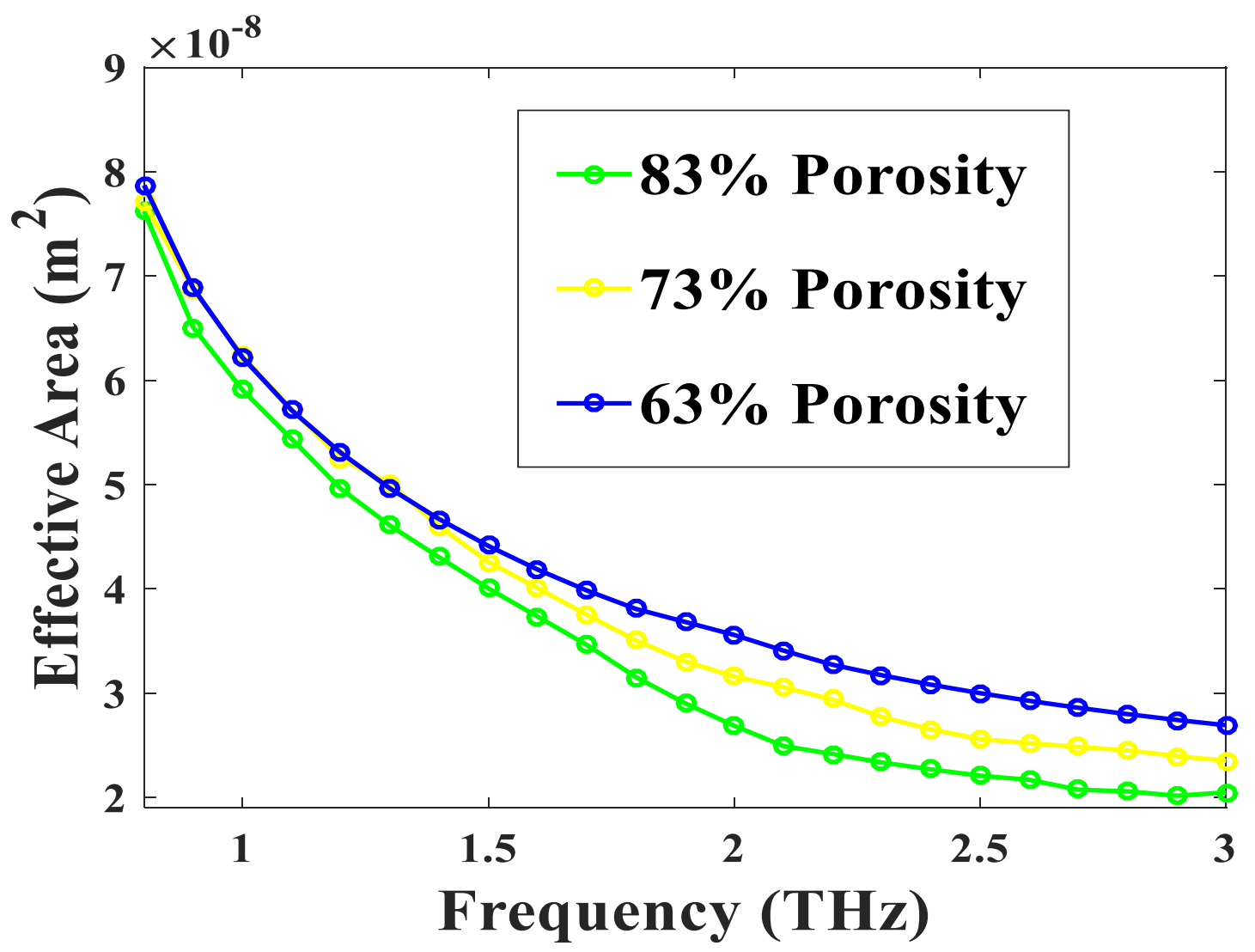

Figure 2: Effective area along with various frequencies for $83 \%, 73 \%$ and $63 \%$ porosities.

In Figure 3 shows the better numerical results of effective area along with the core diameter for different porosities such as $63 \%, 73 \%$, and $83 \%$. Successful effective area decreases with the rise of the core diameter. Moreover, it is seen that the effective area stays flat from $D_{\text {core }}=196 \mu \mathrm{m}$ to $\mathrm{D}_{\text {core }}=390 \mu \mathrm{m}$. For optimum core diameter $\mathrm{D}_{\text {core }}=376 \mu \mathrm{m}$, the effective area is expected as $5.55 \times 10^{-8} \mathrm{~m}^{2}, 6.50 \times 10^{-8} \mathrm{~m}^{2}$, and $7.20 \times 10^{-8} \mathrm{~m}^{2}$ for $83 \%, 73 \%$, and $63 \%$ porosities for 1 terahartz (THz) frequency correspondingly. 


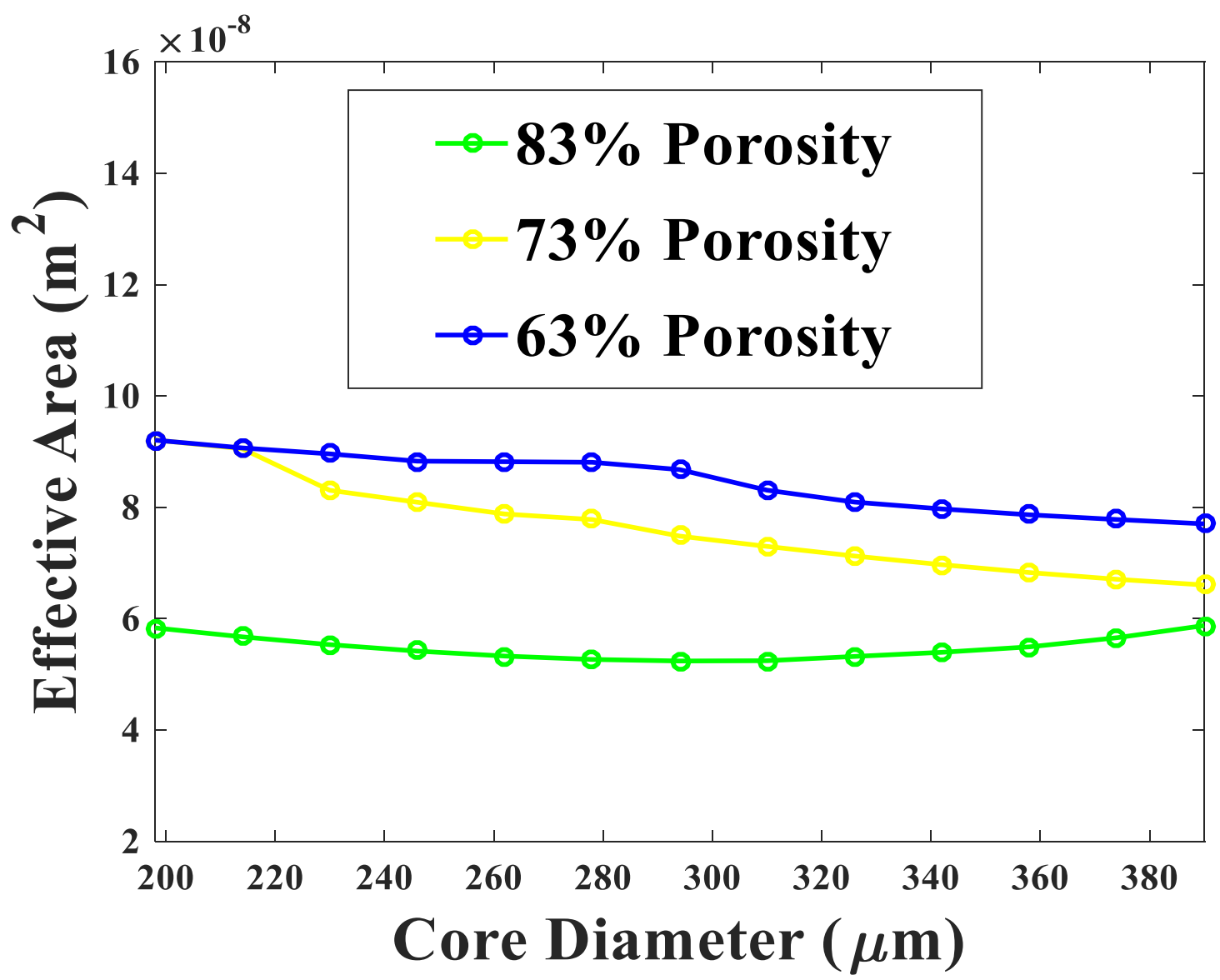

Figure 3: Effective area at various core diameters for $83 \%, 73 \%$ and $63 \%$ porosities with $1 \mathrm{THz}$ frequency.

The effective material loss of the anticipated O-PCF has been given by frequency modification in Figure 4 and the effective material loss reduces with the rising of frequency. This O-PCF fiber shows better effective material losses such as $0.0348 \mathrm{~cm}^{-1}, 0.0236 \mathrm{~cm}^{-1}$ and $0.0162 \mathrm{~cm}^{-1}$ for $63 \%, 73 \%$ and $83 \%$ porosities correspondingly at 1 terahertz $(\mathrm{THz})$ for optimum parameters. 


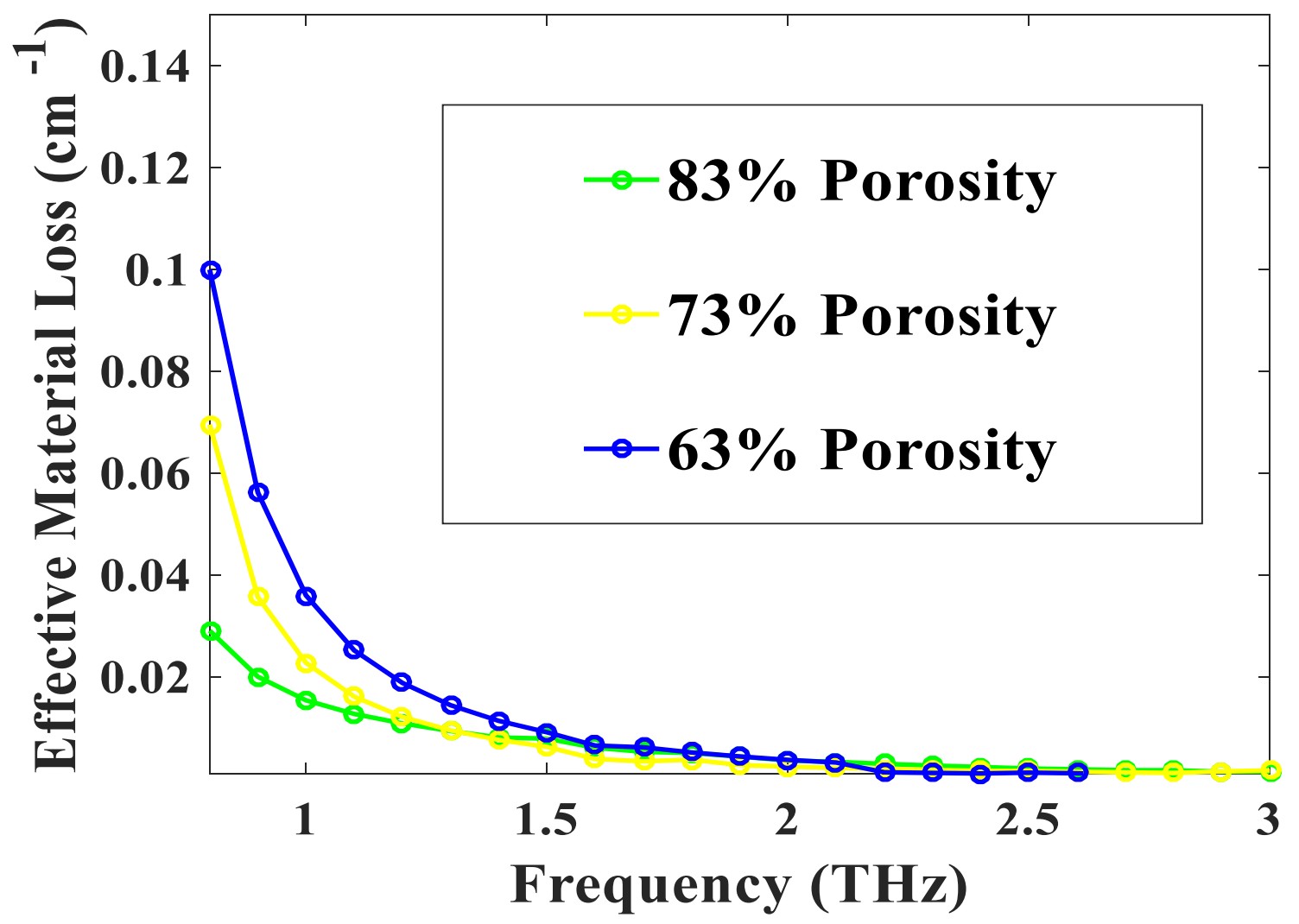

Figure 4: EML versus frequency for $83 \%, 73 \%$ and $63 \%$ porosities.

The effect of various core diameters and the effective material loss for $83 \%, 73 \%$ and $63 \%$ porosities has been shown in Figure 5. Here, the effective material losses is increased with the increasing of core diameters. On the other hand, for $\mathrm{D}_{\text {core }}=376 \mu \mathrm{m}$, porosity $=83 \%, 73 \%$ and $63 \%$ at 1 terahertz $(\mathrm{THz})$ frequency, the effective material loss shows $0.0162 \mathrm{~cm}^{-1}, 0.0187 \mathrm{~cm}^{-}$ $1,0.0137 \mathrm{~cm}^{-1}$ at optimal design parameters. 


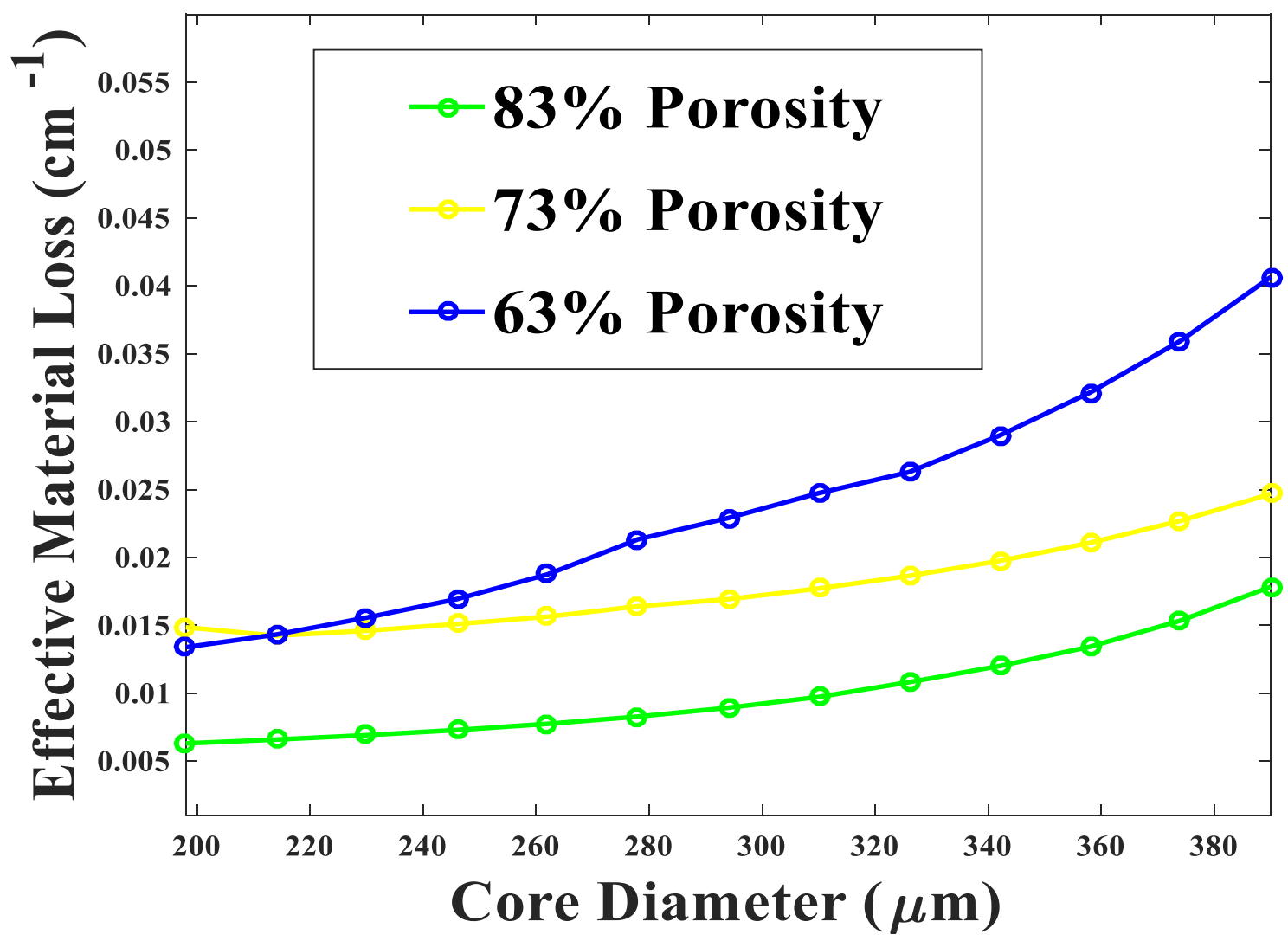

Figure 5: EML versus core diameters for $83 \%, 73 \%$ and $63 \%$ porosities at $1 \mathrm{THz}$ frequency.

Fig. 6 shows the distribution of power across the core, cladding and materials with respect to frequency at a fixed $\mathrm{D}_{\text {core }}=376 \mathrm{um}$. As the light generated within the fiber, some of the power is absorbed by air holes and core materials in the fiber. The experimental frequency ranges within $0.08 \mathrm{THz}$ to $3 \mathrm{THz}$ in electromagnetic band. As it was found that, $80 \%$ optical power generated through the fiber core at 1 terahertz $(\mathrm{THz})$ which means maximum light contact with analytes in the core region. Moreover, the air holes in cladding region induced light waves to pass within the core and provide maximum core power fraction. The observed power fraction is considerably higher than the previously stated article. The power fractions of core, cladding and materials are $80 \%, 2 \%$ and $28 \%$ respectively which operated at $1 \mathrm{THz}$ ranges. 


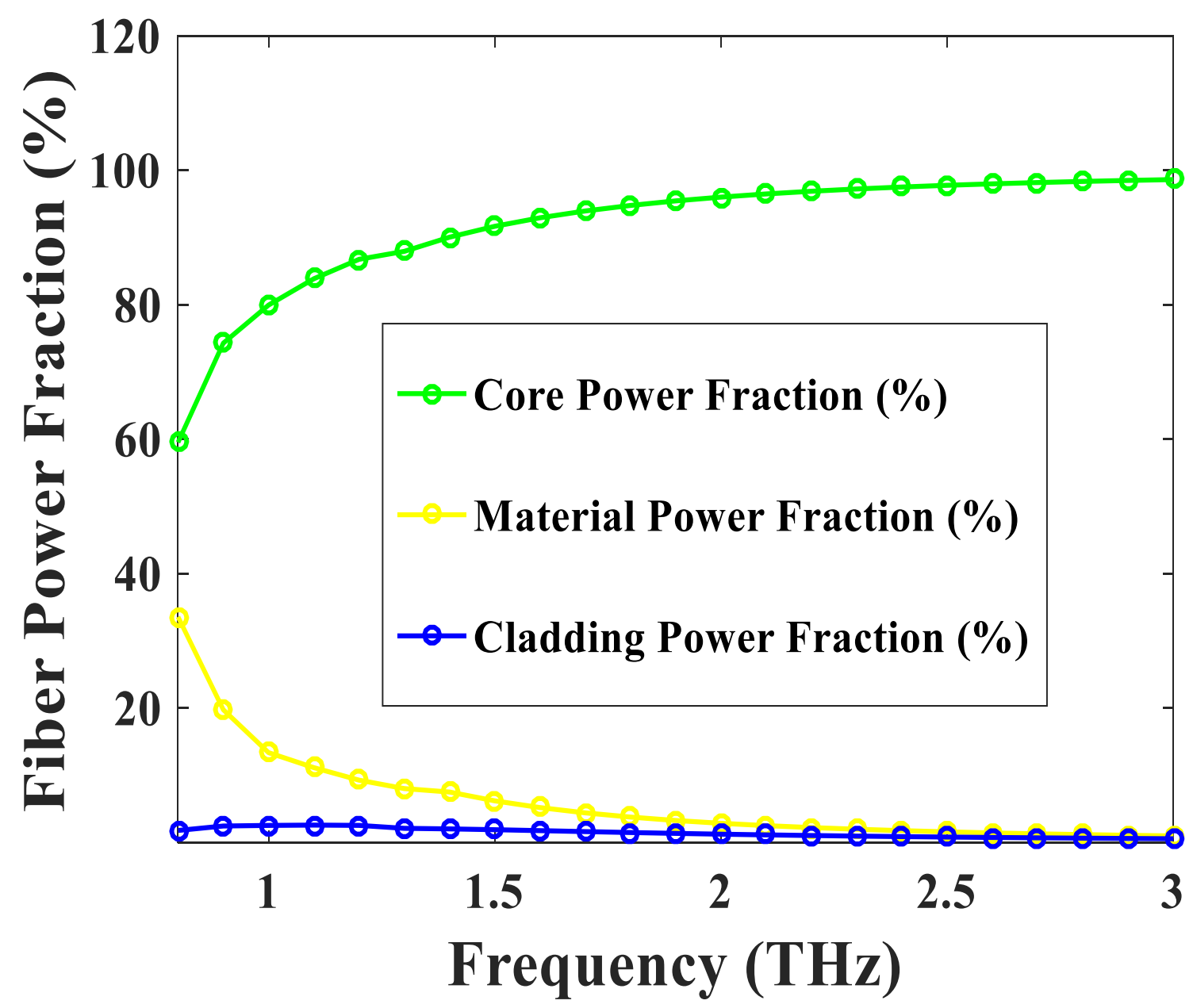

Figure 6: Power fraction versus of various frequencies for optimal design considerations.

Fig. 7 indicates the scattering loss analysis for the variations in wavelength in proposed structure. Therefore, light totally absorbed by the core area and reduce scattering loss. Scattering loss is an important parameter because it contributes the total losses of the fiber. Scattering loss is increasing with the increases of frequency within $0.08-3 \mathrm{THz}$ range appeared in figure 7 , where's the $\mathrm{D}_{\text {core }}=376 \mathrm{um}$. The attained scattering loss $(\mathrm{SL})$ of this O-PCF is $1.22 \times 10^{-10} \mathrm{~dB} / \mathrm{km}$ at optical wavelength 1 terahertz $(\mathrm{THz})$ which is negligible. 


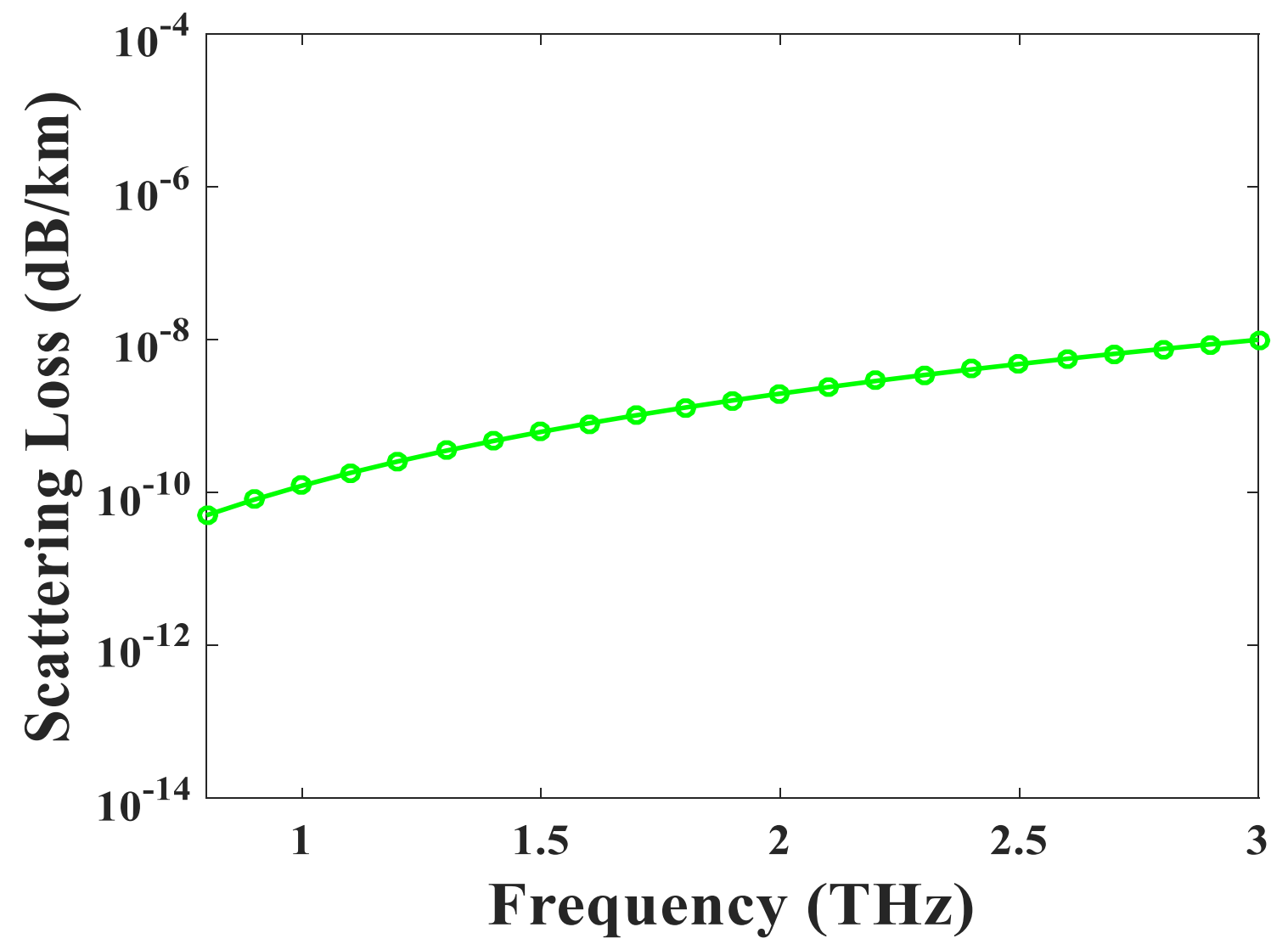

Figure 7: Scattering loss versus frequencies of proposed O-PCF fiber for optimum parameters.

Fig. 8 shows the behavior of confinement loss due to the frequency at optimal structure. It can be observed from the figure, confinement loss of proposed model is being reduced due to rising of frequency across $0.08-3 \mathrm{THz}$ at $\mathrm{D}_{\text {core }}=376 \mathrm{um}$. When light passes through the core with high frequency then it improves the index contrast of core and cladding and thus minimize the confinement loss. It is found that that the confinement loss of proposed O-PCF is $3.33 \times 10^{-14}$ $\mathrm{dB} / \mathrm{m}$. 


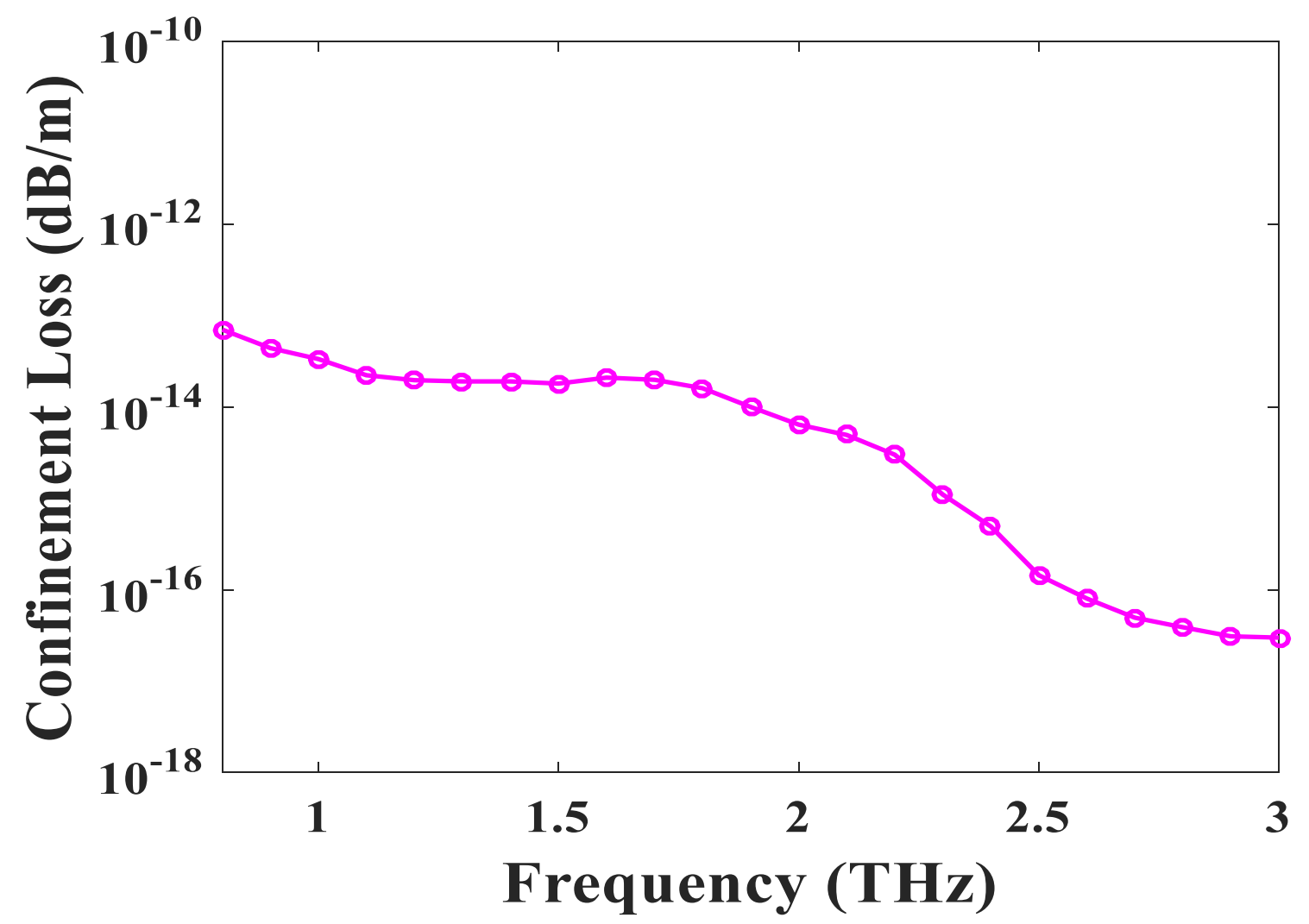

Figure 8: Confinement loss of proposed O-PCF fiber at different frequencies for optimum design parameters.

$\mathrm{V}$-parameter indicates the fiber act as single mode or multimode. V-parameter is calculated as the function of frequency for optimum design parameter at $D_{\text {core }}=376 \mu \mathrm{m}$ in figure 9 . As it evolves that, V-parameter is 1.20 at operating frequency 3 terahertz $(\mathrm{THz})$ which shows the suggested model is single mode fiber ( $\mathrm{SMF} \leq 2.405$ ). On the other hand, single mode fiber is best suitable for wide band communication applications and others communication related signals. Here, the proposed O-PCF design of optimum elements are diameter of cladding $\mathrm{m}_{1}=$ $244 \mu \mathrm{m}, \mathrm{m}_{2}=\mathrm{m}_{3}=\mathrm{m}_{4}=\mathrm{m}_{5}=272 \mu \mathrm{m}$, pitch of cladding $\mathrm{P}_{1}=325 \mu \mathrm{m}, \mathrm{P}_{2}=\mathrm{P}_{3}=\mathrm{P}_{4}=\mathrm{P}_{5}=365 \mu \mathrm{m}$, diameter of core $\mathrm{m}_{\mathrm{a}}=74 \mu \mathrm{m}, \mathrm{m}_{\mathrm{b}}=195 \mu \mathrm{m}$ and core pitch $\mathrm{P}_{\mathrm{c}}=90 \mu \mathrm{m}$. 


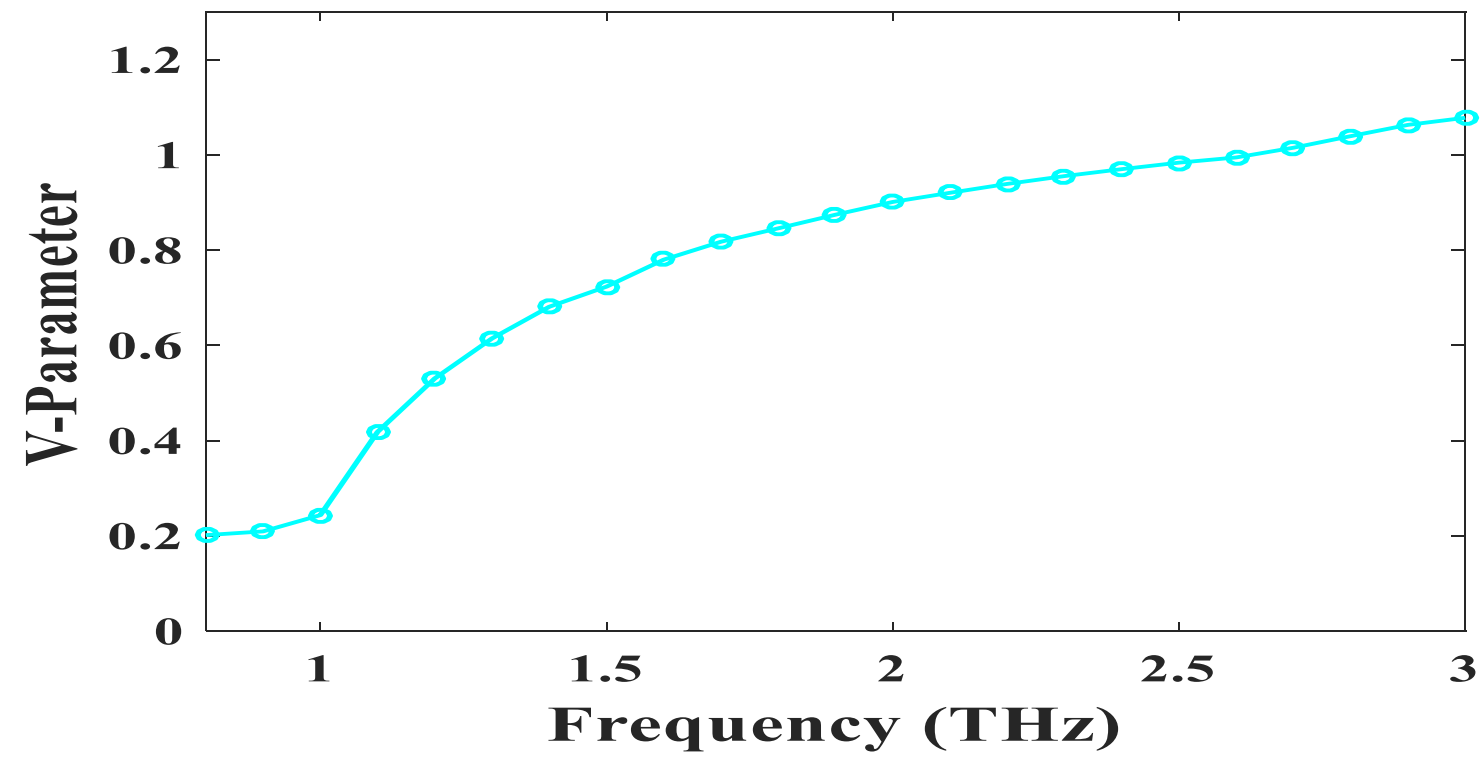

Figure 9: V-parameter of the designed O-PCF is computed at various frequencies for optimum design.

The designed O-PCF shows the better effective material loss, Confinement loss, Core power fraction, and effective area properties than other designed PCFs at 1 terahertz (THz) functional frequency as providing in Table 1.

Table 1: Assessment of guiding properties of proposed O-PCF with the previously designed.

$\begin{array}{lccccc}\text { Ref. } & \begin{array}{c}\text { EML } \\ \left(\mathrm{cm}^{-1}\right)\end{array} & \begin{array}{r}\text { Porosity } \\ (\%)\end{array} & \begin{array}{c}\text { Power } \\ \text { Fraction }\end{array} & \begin{array}{c}\text { Confinement } \\ \text { Loss }(\mathrm{dB} / \mathrm{m})\end{array} & \begin{array}{c}\text { Effective } \\ \text { Area }\left(\mathrm{A}_{\text {eff }}\right. \\ \left.\left(\mathrm{m}^{2}\right)\right)\end{array} \\ {[39]} & 0.100 & 30 & - & 1.0 \times 10^{-01} & 2.3 \times 10^{-07} \\ {[40]} & 0.089 & 60 & 37 \% & 1.0 \times 10^{-02} & 9.77 \times 10^{-08} \\ {[41]} & 0.076 & 80 & 53 \% & 8.96 \times 10^{-01} & - \\ {[42]} & 0.038 & 74 & 56 \% & 2.35 \times 10^{-01} & 6.75 \times 10^{-05} \\ {[43]} & 0.110 & - & - & - & 0.98 \times 10^{-07} \\ {[44]} & 0.027 & 85 & 83 \% & 1.0 \times 10^{-02} & 9.48 \times 10^{-08} \\ {[45]} & 0.068 & 50 & - & - & - \\ {[46]} & 0.050 & 60 & 42 \% & 1.00 & - \\ {[47]} & 0.07 & 30 & - & 1.14 \times 10^{-3} & 1.07 \times 10^{-9} \\ {[48]} & 0.05 & - & 67 \% & 7.79 \times 10^{-12} & 2.00 \times 10^{-5} \\ {[49]} & 0.078 & 30 & - & 1.39 \times 10^{-4} & -\end{array}$




$\begin{array}{cccccc}{[50]} & 0.043 & 81 & 47 \% & 1.00 \times 10^{-2} & 2.15 \times 10^{-5} \\ \begin{array}{c}\text { Proposed } \\ \text { O-PCF }\end{array} & 0.0162 & 83 & 80 \% & 3.33 \times 10^{-14} & 5.88 \times 10^{-8}\end{array}$

From the investigation of Table 1 that the proposed O-PCF will play an essential role in various wideband transmission applications in $\mathrm{THz}$ micro-technology. On the other hand, fabrication technique is an important issue of any PCF structure. So, many fabrication techniques are appropriate essentially to fabricate the O-PCF [51-52] but sol-gel [53] procedure is more appropriate for fabricate the O-PCF.

\section{Conclusion}

In this proposed work, Zeonex based two elliptical shape air holes of the core region along with octagonal shape circular air holes of cladding region have been thoroughly examined using the PML boundary structure with the FEM based COMSOL Multiphysics. After the numerical procedure, our reported O-PCF fiber gives an outstanding optical property such as a low effective material loss (EML) of $0.0162 \mathrm{~cm}^{-1}$, the larger effective area of $5.88 \times 10^{-8} \mathrm{~m}^{2}$, the core power fraction (PF) of $80 \%$, the scattering loss (SL) of $1.22 \times 10^{-10} \mathrm{~dB} / \mathrm{km}$ and the confinement loss of $3.33 \times 10^{-14} \mathrm{~dB} / \mathrm{m}$ at the operating region of 1 terahertz $(\mathrm{THz})$. Therefore, our proposed OPCF structure will be used in many communication applications for its excellent optical properties.

Conflict of Interest: The authors announce that they have no conflict of interest.

Acknowledgement: The authors do not receive any funding for this research work.

\section{References:}

[1] D. Vigneswaran, M. S. Mani Rajan, Bipul Biswas, Amit Grover, Kawsar Ahmed, Bikash Kumar Paul, Numerical investigation of spiral photonic crystal fiber (S-PCF) with supporting higher order OAM modes propagation for space division multiplexing applications, Optical and Quantum Electronics 53 (2021)78

[2] V. Devika and M. S. Mani Rajan, Hexagonal PCF of honeycomb lattice with high birefringence and high nonlinearity, International Journal of Modern Physics B (World Scientific), 33 (2020) 2050094.

[3] Md. Anowar Kabir, Md. Mehedi Hassan, Kawsar Ahmed, M.S. Mani Rajan, Arafa H Aly, Md. Nadim Hossain, Bikash Kumar Paul, Novel Spider Web Photonic Crystal Fiber for Robust Mode Transmission applications with Supporting Orbital Angular Momentum Transmission Property, Optical and Quantum Electronics 52(2020)331. 
[4] Aparna A. Nair, C.S. Boopathi, M. Jayaraju, M.S. Mani Rajan, Numerical investigation and analysis of flattened dispersion for supercontinuum generation at very low power using Hexagonal shaped Photonic crystal fiber (H-PCF), Optik 179 (2019) 718-725.

[5] Mohit Sharma, D. Vigneswaran, Julia S. Skibina, M.S. Mani Rajan, S. Konar, T. T. Hoang and Q. M. Ngo, Giant Nonlinear AlGaAs-Doped Glass Photonic Crystal Fibers for Efficient Soliton Generation at Femtojoule Energy, IEEE Photonics, 11 (2019) 7102411.

[6] E. R. Vera, J. U. Restrepo, C. J. Durango, J. M. Cardona and N. G. Cardona. Design of Low Loss and Highly Birefringent Porous Core Photonic Crystal Fiber and its application to Terahertz Polarization Beam Splitter. IEEE Photonic Journal, vol. 10, no. 4(2018)

[7] Ho, L., Pepper, M., \& Taday, P. Terahertz spectroscopy: Signatures and fingerprints. Nature Photonics, 2(9), 541 (2008)

[8] S. Rana, A. S. Rakin, M. R. Hasan, M. S. Reza and R. Leonhardt. Low Loss and flat Dispersion Kagome Photonic Crystal Fiber in the Terahertz Regime. Optics Communications, vol. 410, pp. 452-456 (2018)

[9] MS. Hossain, S. Shuvo, M.M. Hossain. Design of a chemical sensing circular photonic crystal fiber with high relative sensitivity and low confinement loss for terahertz (THz) regime, Optik - International Journal for Light and Electron Optics, Vol. 222(2020), 165359, https://doi.org/10.1016/j.ijleo.2020.165359 (2020)

[10] Jianying Zhou, Yu Zheng. Fiber refractive index sensor with lateral-offset micro-hole fabricated by femtosecond laser. Optik, Volume 185,2019, Pages 1-7, ISSN 0030-4026, https://doi.org/10.1016/j.ijleo.2019.03.094(2019)

[11] NR Ramanujam, KS Joseph Wilson, P. Mahalakshmi, Sofyan A. Taya. Analysis of photonic band gap in photonic crystal with epsilon negative and double negative materials. Optik, Volume 183, Pages 203-210, ISSN 0030-4026, https://doi.org/10.1016/j.ijleo.2019.02.066(2019)

[12] Jin, Y. S., Kim, G. J., \& Jeon, S. G. Terahertz dielectric properties of polymers. Journal of the Korean Physical Society, 49(2), 513-517 (2006)

[13] H. Ilatikhameneh, T. Ameen, F. Chen, H. Sahasrabudhe, G. Klimeck and R. Rahman. Dramatic Impact of Dimensionality on the Electrostatics of P-N Junctions and Its Sensing and Switching Applications. IEEE Transactions on Nanotechnology. doi:10.1109/TNANO.2018.2799960 (2018)

[14] Chen, L. J., Chen, H. W., Kao, T. F., Lu, J. Y., \& Sun, C. K. Low-loss subwavelength plastic fiber for terahertz waveguiding. Optics Letters, 31(3), 308-310 (2006)

[15] Lu, J. Y., Yu, C. P., Chang, H. C., Chen, H. W., Li, Y. T., Pan, C. L., \& Sun, C. K. Terahertz air-core microstructure fiber. Applied Physics Letters, 92(6), 064105(2008)

[16] T. Ritari, J. Tuominen, H. Ludvigsen, J.C. Petersen, T. Sorensen, T.P. Hansen, H.R. Simonsen, Gas sensing using air-guiding photonic bandgap fibers, Opt. Express, 4080-4087(2004)

[17] Ademgil, H., Haxha, S., \& Abdel Malek, F. Highly nonlinear bending-insensitive birefringent photonic crystal fibres. Engineering, 2(08), 608(2010)

[18] Lee, J. H., Teh, P. C., Yusoff, Z., Ibsen, M., Belardi, W., Monro, T. M., \& Richardson, D. J. A holey fiberbased nonlinear thresholding device for optical CDMA receiver performance enhancement. IEEE Photonics Technology Letters, 14(6), 876-878 (2002)

[19] Devi D. Structural parameters, electronic properties, and band gaps of a single walled carbon nanotube: A pz orbital tight binding study. Superlattices and Microstructures. https://doi.org/10.1016/j.spmi.2018.05.023(2018)

[20] Shuvo S., Shafi M.A, Sikder A.S., Hossain Md.S., Azad M.M. Zeonex based decagonal photonic crystal fiber (D-PCF) in the terahertz (THz) band for chemical sensing applications. Sensing and Bio-Sensing Research. https://doi.org/10.1016/j.sbsr.2020.100393(2020)

[21] Hossain, M.S., Sen, S. Design and Performance Improvement of Optical Chemical Sensor Based Photonic Crystal Fiber (PCF) in the Terahertz (THz) Wave Propagation. Silicon. https://doi.org/10.1007/s12633020-00696-8(2020) 
[22] Islam, M. S., Sultana, J., Dorraki, M., Atai, J., Islam, M. R., Dinovitser, A., ... \& Abbott, D. Low loss and low dispersion hybrid core photonic crystal fiber for terahertz propagation. Photonic Network Communications, 35(3), 364-373(2018)

[23] Kaijage, S. F., Ouyang, Z., \& Jin, X. Porous-core photonic crystal fiber for low loss terahertz wave guiding. IEEE Photonics Technology Letters, 25(15), 1454-1457 (2013)

[24] K. Ahmen, B. K. Paul, S. Chowdhury, S. Sen, M. I. Islam, M. S. Islam. Design of a single mode photonic Crystal fiber with ultra-low material loss and large effective mode area in $\mathrm{THz}$ regime. IET Optoelectronics, vol. 11, no. 6, pp. 265-271, 2017.

[25] Hasanuzzaman, G. K. M., Habib, M. S., Razzak, S. A., Hossain, M. A., \& Namihira, Y. Low loss singlemode porous-core kagome photonic crystal fiber for $\mathrm{THz}$ wave guidance. Journal of Lightwave Technology, 33(19), 4027-4031(2015).

[26] M. M. Rahman, F. A. Mou, M. I. H. Bhuiyan and M. R. Islam. Extremely Low Effective Material Loss of Air Core Photonic Crystal Fiber for THz Guidance. IEEE Region 10 Symposium (TENSYMP), Kolkata, India, 2019, pp. 716-720, doi: 10.1109/TENSYMP46218.2019.8971297(2019)

[27] R. K. Gangwar and V. K. Singh. Study of highly birefringence dispersion shifted photonic crystal fiber with asymmetrical cladding. Optic, vol. 127, no. 24, pp. 11854-11859(2016)

[28] Hasan, M. R., Akter, S., Khatun, T., Rifat, A. A., \& Anower, M. S. Dual-hole unit-based kagome lattice microstructure fiber for low-loss and highly birefringent terahertz guidance. Optical Engineering, 56(4), 043108(2017)

[29] Y. S. Lee, C. G. Lee, Y. Jung, M. K. Oh and S. Kim. Highly Birefringent and dispersion compensating photonic crystal fiber based on double line defect core. J. of Opt. Soc. of Korea, vol. 20, no. 5, pp. 567574(2016)

[30] Hossain, M.S, Shuvo S., Hossain, M.M. Design of a chemical sensing circular photonic crystal fiber with high relative sensitivity and low confinement loss for terahertz $(\mathrm{THz})$ regime. Optik - International Journal for Light and Electron Optics, Vol. 222 (2020) 165359, https://doi.org/10.1016/j.ijleo.2020.165359(2020)

[31] R. Islam, S. Rana, R. Ahmad and S. F. Kaijage, "Bend-Insensitive and Low-Loss Porous Core Spiral Terahertz Fiber," in IEEE Photonics Technology Letters, vol. 27, no. 21, pp. 2242-2245, 1 Nov.1, 2015, doi: 10.1109/LPT.2015.2457941

[32] Hasan, M.R.; Islam, M.A.; Anower, M.S.; Razzak, S.M.A. Low-loss and bend-insensitive terahertz fiber using a rhombic-shaped core. Appl. Opt. 2016, 55, 8441-8447

[33] Islam, M.S., Rana, S., Islam, M.R., Faisal, M., Rahman, H., Sultana, J.: Porous core photonic crystal fiber for ultra-low material loss in THz regime. IET Commun. 10(16), 2179-2183 (2016)

[34] Rana, S., Rakin, A. S., Hasan, M. R., Reza, M. S., Leonhardt, R., Abbott, D., \& Subbaraman, H. (2018), "Low loss and flat dispersion Kagome photonic crystal fiber in the terahertz regime". Optics Communications, 410, 452-456.

[35] Sultana, J., Islam, M.S., Faisal, M., Islam, M.R., Ng, B.W.H., Ebendorf-Heidepriem, H., Abbott, D.: Highly birefringent elliptical core photonic crystal fber for terahertz application. Opt. Commun.407, 92-96 (2018)

[36] M. S. Hossain, M. M. Hasan, S. Sen, M. S. H. Mollah, and M. M. Azad, Simulation and analysis of ultralow material loss of single-mode photonic crystal fiber in terahertz $(\mathrm{THz})$ spectrum for communication applications, J. Opt. Commun., vol. 4873, 2021, doi: 10.1515/joc-2020-0224.

[37] F. A. Mou, M. M. Rahman, A. A. Mahmud, M. I. H. Bhuiyan and M. R. Islam. Design and Characterization of a Low Loss Polarization Maintaining Photonic Crystal Fiber for THz Regime. IEEE International Conference on Telecommunications and Photonics (2019).

[38] F. A. Mou, M. M. Rahman, M. R. Islam and M. I. H. Bhuiyan, "Development of a photonic crystal fiber for $\mathrm{THz}$ wave guidance and environmental pollutants detection", Sensing and Bio-Sensing Research, vol. 29, no. 100346(2020) 
[39] Islam R, Rana S, Ahmad R, Kaijage SF. Bend-insensitive and low-loss porous core spiral terahertz fiber. IEEE Photon Technol Lett. 2015; 27(21):2242-2245. DOI:10.1109/LPT.2015.2457941.

[40] Hasan MR, Islam MA, Anower MS, Razzak SM. Low-loss and bend-insensitive terahertz fiber using a rhombic-shaped core. Appl Opt. 2016; 55(30):8441-8447. DOI:10.1364/AO.55.008441.

[41] Hasan MR, Islam MA, Rifat AA. A single mode porous-core square lattice photonic crystal fiber for THz wave propagation Eur Opt Soc Rapid Publ. 2016;12(1):15. DOI:10. 1186/s41476-016-0017-5.

[42] Paul BK, Ahmed K. Analysis of terahertz waveguide properties of Q-PCF based on FEM scheme. Opt Mater. 2020; 100:109634.

[43] Islam R, Habib MS, Hasanuzzaman GKM, Rana S, Sadath MA, Markos C. A novel low-loss diamond-core porous fiber for polarization maintaining terahertz transmission. IEEE Photon Technol Lett. 2016; 28(14):1537-1540.

[44] Paul BK, Bhuiyan T, Abdulrazak LF, Sarker K, Hassan MM, Shariful S, Ahmed K. extremely low loss optical waveguide for terahertz pulse guidance. Results in Physics. 2019; 15:102666.

[45] Ahmed K, Chowdhury S, Paul BK, Islam MS, Sen S, Islam MI,et al. Ultrahigh birefringence, ultralow material loss porous core single-mode fiber for terahertz wave guidance. Appl Opt. 2017;56(12):34773483. DOI:10.1364/AO.56.003477.

[46] Rana S, Hasanuzzaman GK, Habib S, Kaijage SF, Islam R.Proposal for a low loss porous core octagonal photonic crystal fiber for T-ray wave guiding. Opt Eng. 2014;53(11):115107-115107. DOI:10.1117/1.OE.53.11.115107.

[47] Ahasan Habib, M., Shamim Anower, M., \& Rabiul Hasan, M. Highly birefringent and low effective material loss microstructure fiber for THz wave guidance. Optics Communications. 2018; 423, 140-144. doi: 10.1016/j.optcom.2018.04.022

[48] Sultana, J., Islam, M. S., Ahmed, K., Dinovitser, A., Ng, B. W.-H., \& Abbott, D. Terahertz detection of alcohol using a photonic crystal fiber sensor. Applied Optics. 2018; 57(10), 2426. doi:10.1364/ao.57.002426

[49] Sultana, J., Islam, M. S., Islam, M. R., \& Abbott, D. High numerical aperture, highly birefringent novel photonic crystal fibre for medical imaging applications. Electronics Letters. 2018; 54(2), 61-62. doi:10.1049/el.2017.3694

[50] Islam, M. S., Sultana, J., Rana, S., Islam, M. R., Faisal, M., Kaijage, S. F., \& Abbott, D. Extremely low material loss and dispersion flattened TOPAS based circular porous fiber for long distance terahertz wave transmission. Optical Fiber Technology. 2017; 34, 6-11. doi: 10.1016/j.yofte.2016.11.014

[51] Islam, M.S., Sultana, J., Atai, J., Abbott, D.,Rana, S., Islam, M.R.: Ultra low loss hybrid core porous fiber for broadband applications. Appl. Opt. 56(9), 1232-1237 (2017)

[52] Tang, X., Jiang, Y., Sun, B., Chen, J., Zhu, X., Zhou, P., Wu, D., Shi,Y.: Elliptical hollowfiberwith inner silver coating for linearly polarized terahertz transmission. IEEE Photonics Technol. Lett. 25(4), 331-334 (2013)

[53] El Hamzaoui, H., Ouerdane, Y., Bigot, L., Bouwmans, G., Capoen, B., Boukenter, A., Girard, S. and Bouazaoui, M. Sol-gel derived ionic copper-doped microstructure optical fiber: a potential selective ultraviolet radiation dosimeter. Optics express, 20(28), pp.29751-29760 (2012). 

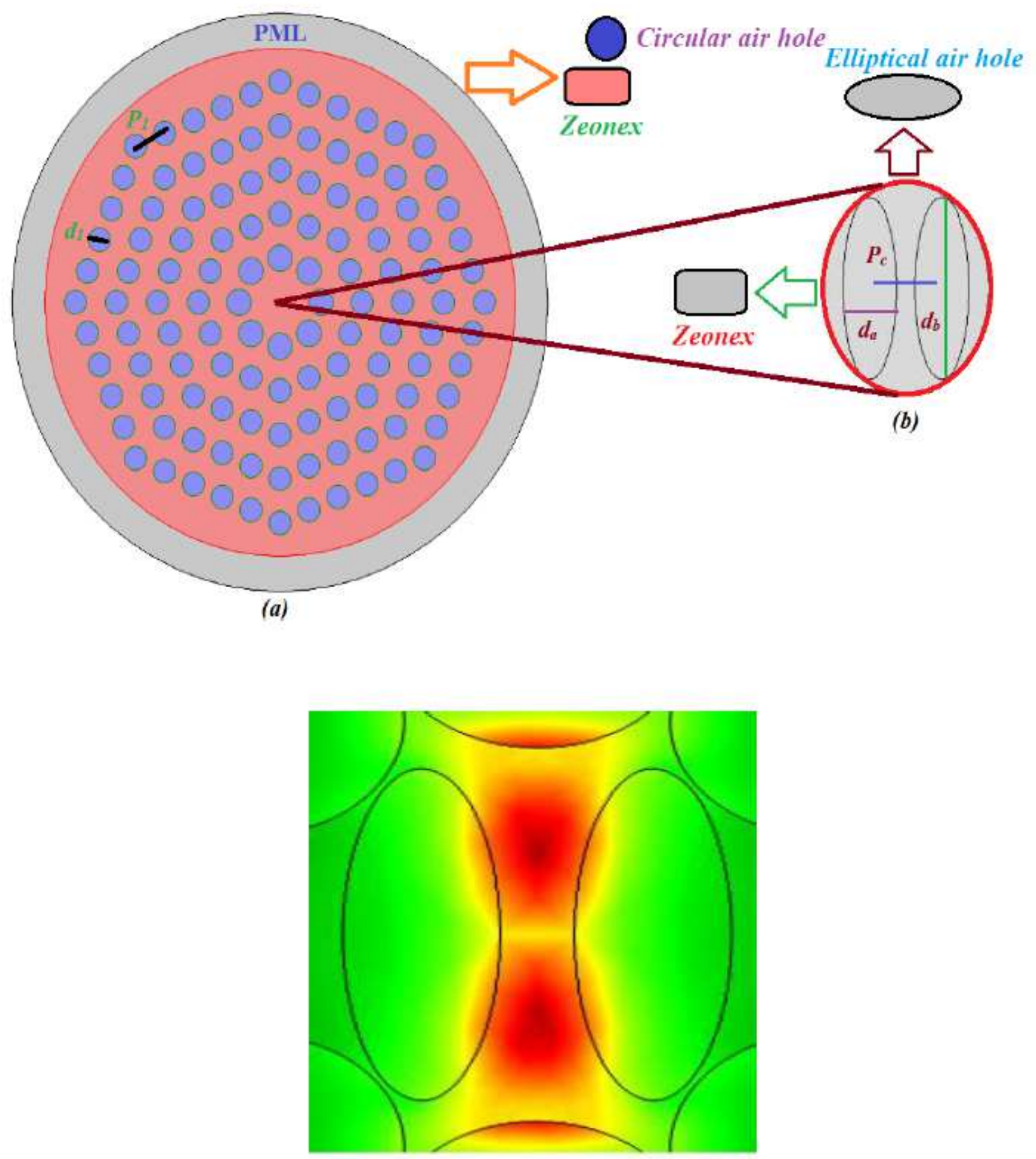

(c) Mode field distribution

\section{Figure 1}

Designing views of O PCF fiber, (a) Octagonal cladding area (b) Elliptical core area (c) Mode field distribution. 


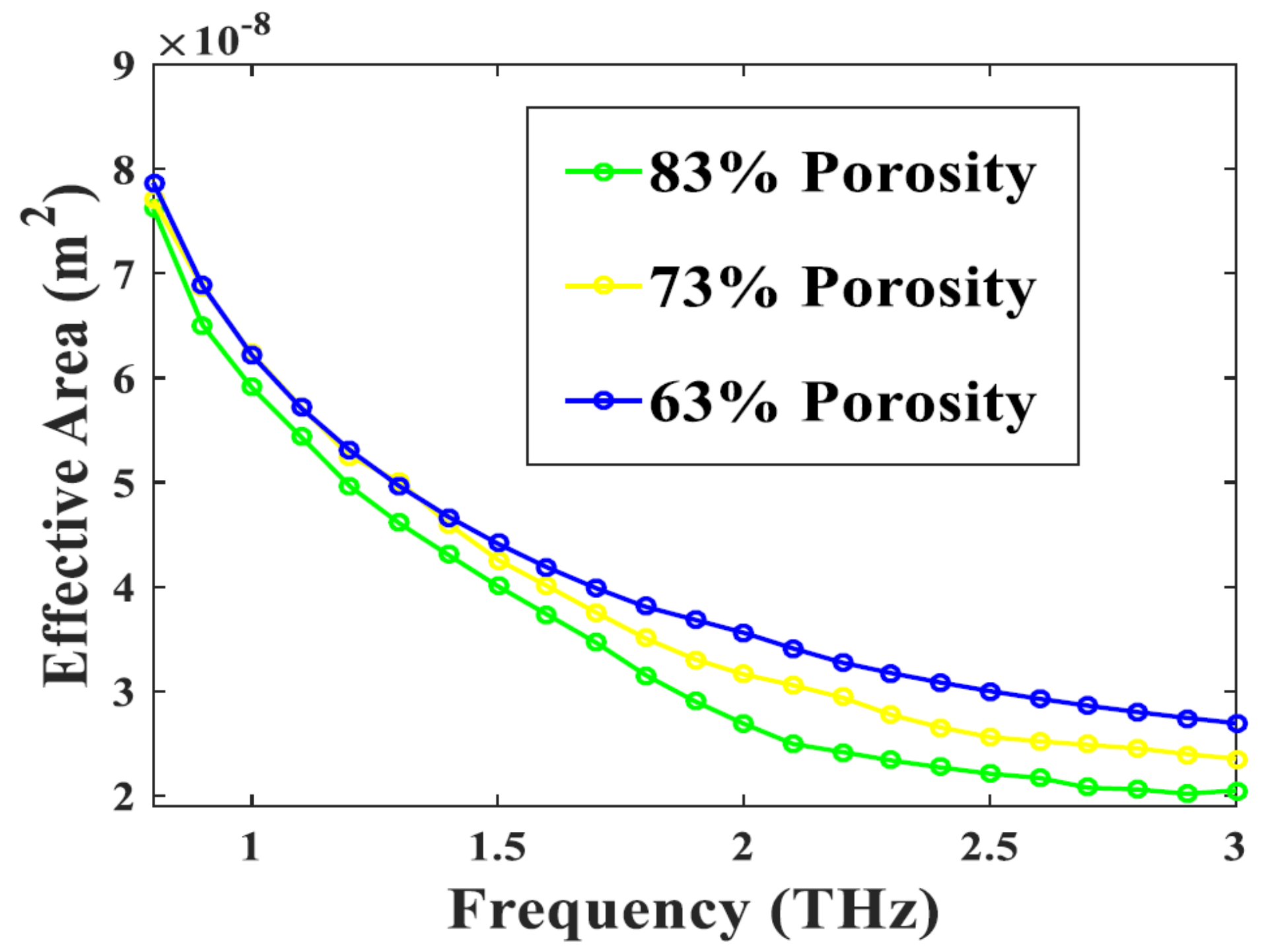

Figure 2

Effective area along with various frequencies for $83 \%, 73 \%$ and $63 \%$ porosities. 


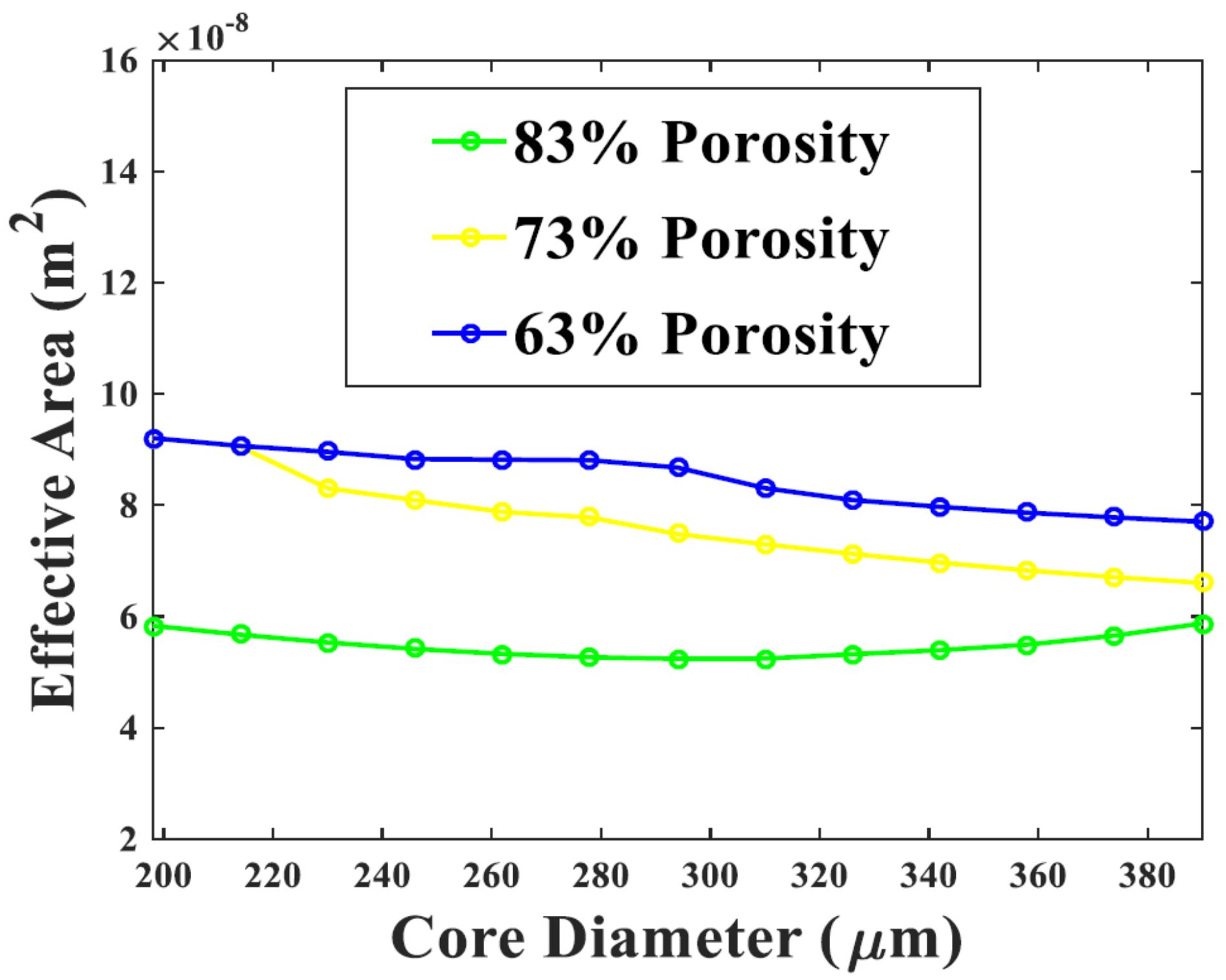

Figure 3

Effective area at various core diameters for $83 \%, 73 \%$ and $63 \%$ porosities with $1 \mathrm{THz}$ frequency. 


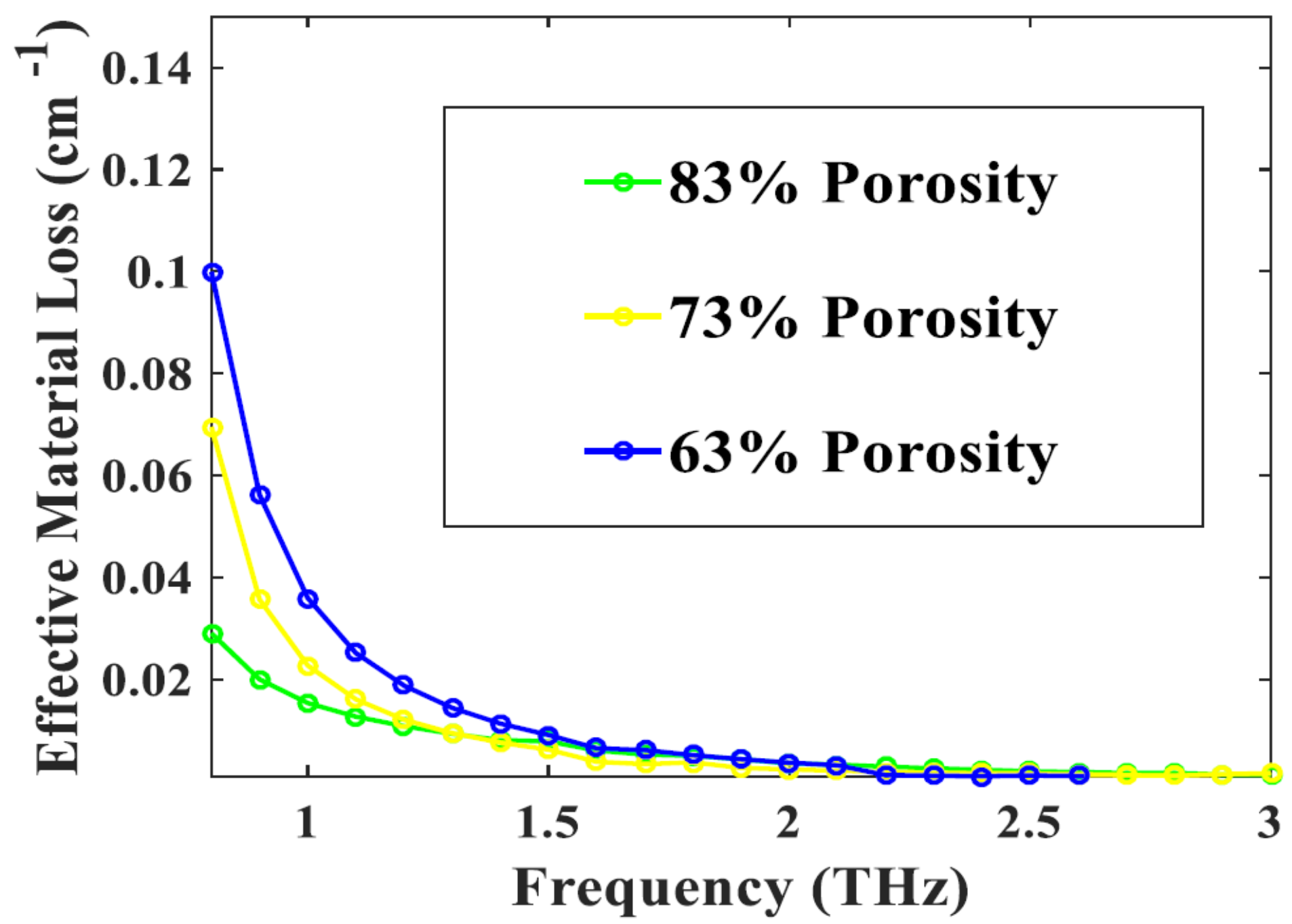

Figure 4

EML versus frequency for $83 \%, 73 \%$ and $63 \%$ porosities. 


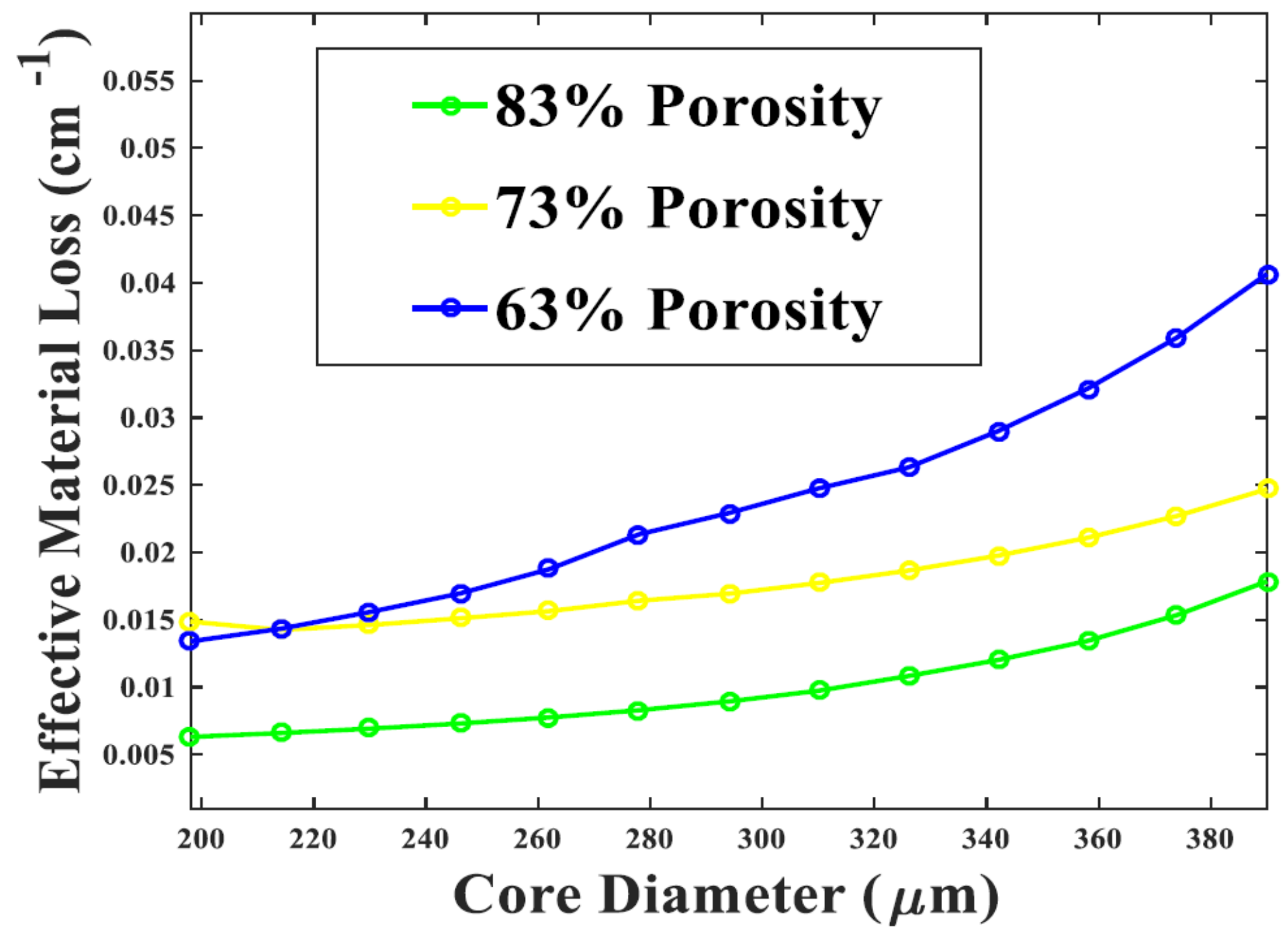

Figure 5

EML versus core diameters for $83 \%, 73 \%$ and $63 \%$ porosities at $1 \mathrm{THz}$ frequency. 


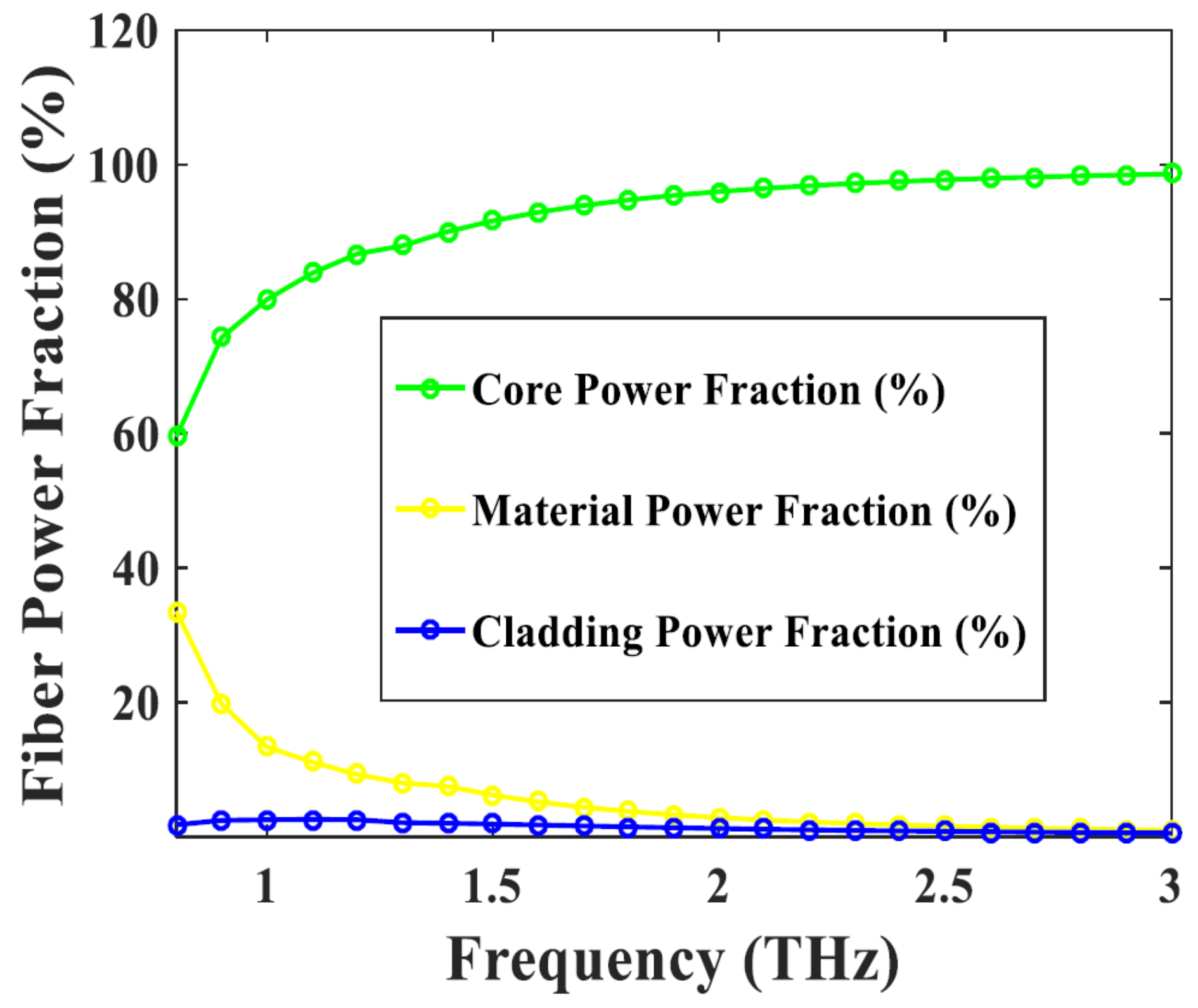

Figure 6

Power fraction versus of various frequencies for optimal design considerations. 


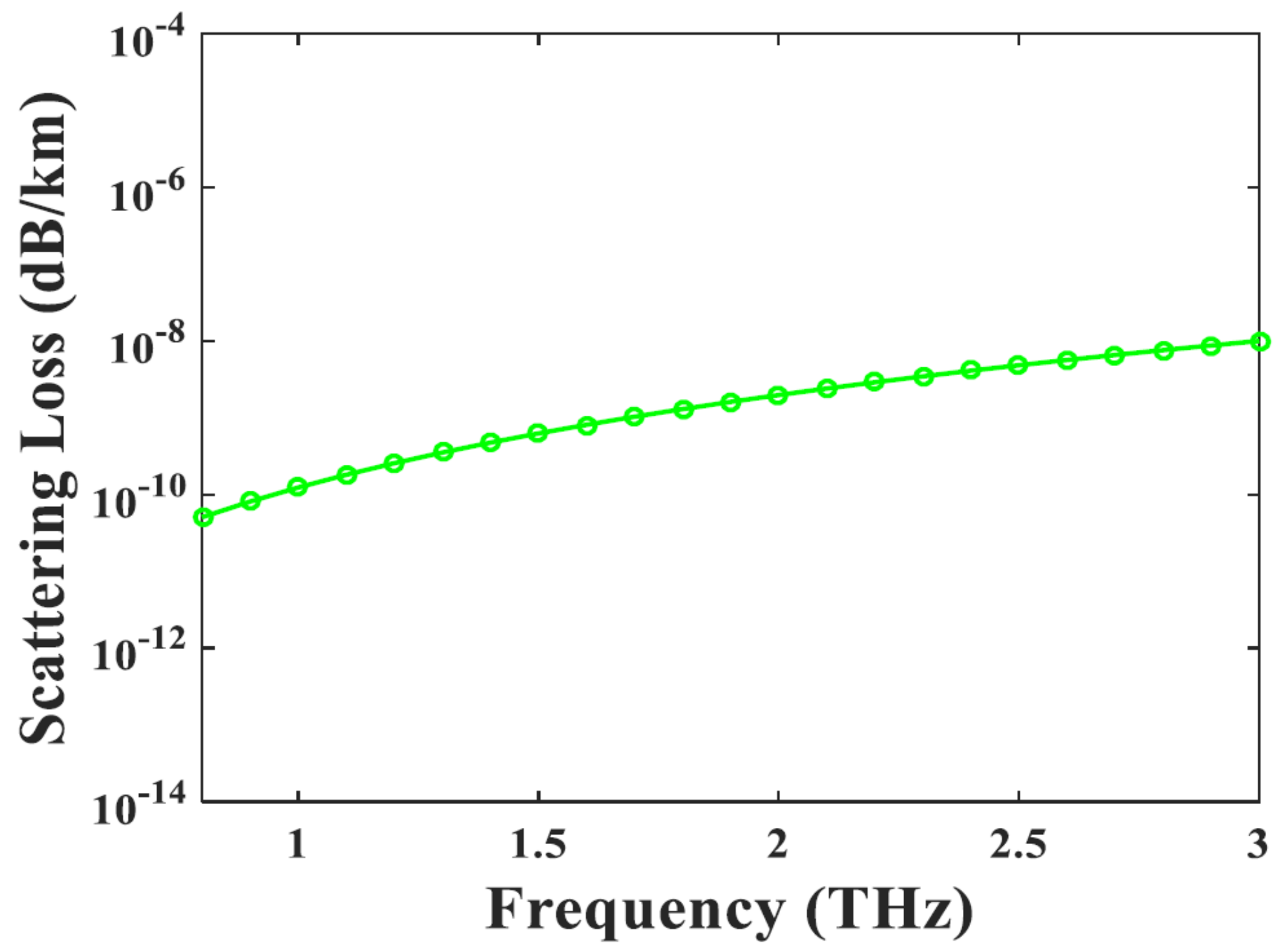

Figure 7

Scattering loss versus frequencies of proposed O-PCF fiber for optimum parameters. 


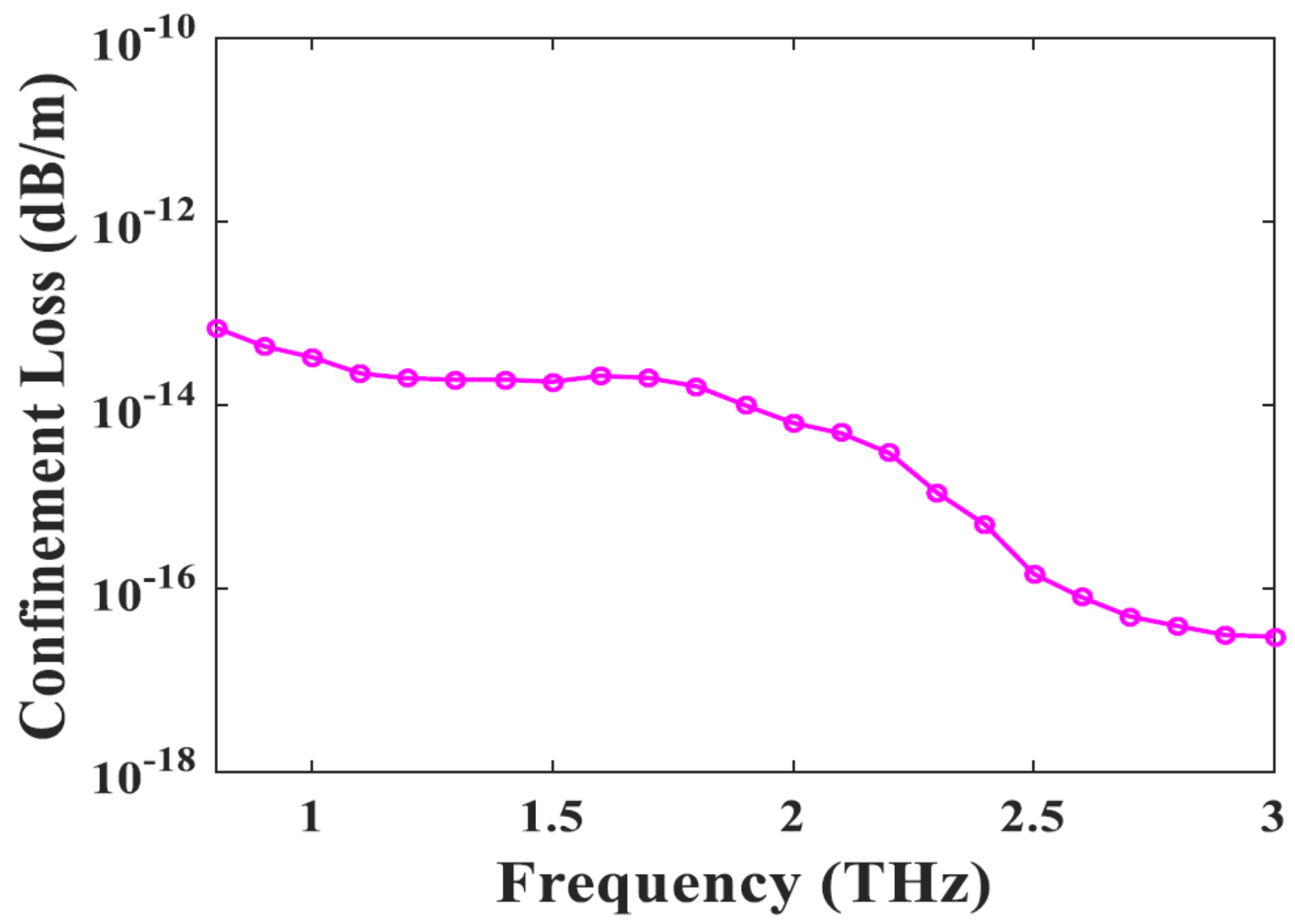

Figure 8

Confinement loss of proposed O-PCF fiber at different frequencies for optimum design parameters. 


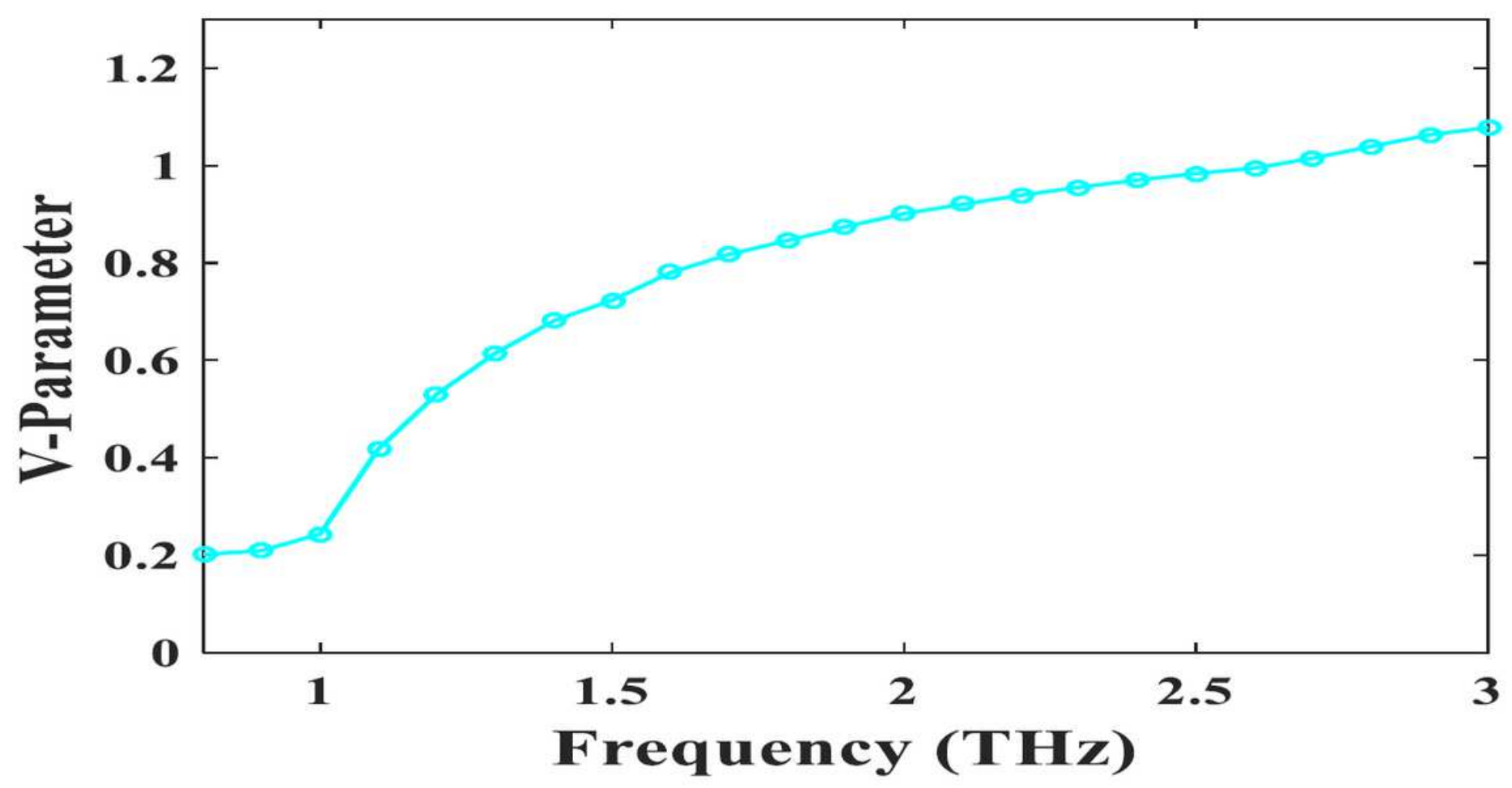

Figure 9

V-parameter of the designed O-PCF is computed at various frequencies for optimum design. 